\title{
Anterior chest wall reconstruction for oncologic and non-oncologic pathology: a case series
}

\author{
Domenica Giunta ${ }^{1}$, Niccolò Daddi ${ }^{1}$, Filippo Antonacci ${ }^{1}$, Valentina Pinto ${ }^{2}$, Piergiorgio Solli ${ }^{1}$, \\ Giampiero Dolci ${ }^{1}$
}

${ }^{1}$ Department of Cardiothoracic and Vascular Surgery, ${ }^{2}$ Department of Plastic and Reconstructive Surgery, University Hospital S. Orsola Malpighi, Bologna, Italy

Contributions: (I) Conception and design: G Dolci; (II) Administrative support: D Giunta; (III) Provision of study materials or patients: D Giunta; (IV) Collection and assembly of data: N Daddi; (V) Data analysis and interpretation: F Antonacci; (VI) Manuscript writing: All authors; (VII) Final approval of manuscript: All authors.

Correspondence to: Giampiero Dolci. Department of Cardio-Thoracic and Vascular Surgery, University Hospital S Orsola Malpighi, Bologna, Italy. Email: dolci.giampiero@gmail.com.

Background: Utmost malignant, in addition to large benign tumors or deformity/trauma of the chest wall, typically require thoracic surgery to manage the abnormal growth promptly. Chest wall resection encompasses a variety of approaches from partial to full surgical removal of soft tissue, cartilage, sternum, and ribs. The reconstruction, using prosthetic materials may be employed to rebuild the skeletal structure.

Methods: From January 2017 to October 2019, four consecutive patients with anterior chest diseases underwent surgical treatment. Two young patients, one with displaced traumatic sternum fracture and the other with pectus carinatum (pigeon breast), were treated by anterior chest wall resection and reconstruction with absorbable pin and titanium plating application. Two adult women with previous breast cancer, one with radio-induced sternum osteosarcoma and the other with post-actinic wall infection were treated using titanium plating application and myocutaneous flaps.

Results: In both two young patients, we had good results correcting the deformities and then fixing it by using a combination of different materials. Patients and parents describe an improved emotional comfort and self-confidence, as well as an increased physical and welfare activities from pre- to post-surgery. Postoperative course was complicated for both women with previous surgery and radiotherapy for breast cancer. Both cases had skin dehiscence and needed further surgical revision. However, long-term follow-up confirms the good cosmetic result, with a satisfactory reconstruction and normal movement.

Conclusions: We reported a small case series of four patients treated for a wide spectrum of different diseases with 4 different techniques. Considering the results, an aggressive, well-planned and multidisciplinary surgical treatment can give excellent success.

Keywords: Chest wall; chest trauma; chest tumor; pectus excavatum; pectus carinatum; case series

Received: 09 December 2019; Accepted: 10 February 2020; Published: 25 August 2020.

doi: $10.21037 /$ ccts.2020.02.05

View this article at: http://dx.doi.org/10.21037/ccts.2020.02.05

\section{Introduction}

The physiologic shape of the chest wall is fundamental for correct respiratory dynamics and in protecting the organs contained in the thorax (1); hence, chest wall reconstruction is of paramount importance and can be a challenging procedure in the area of thoracic surgery.

Chest wall disease may involve an extensive area of excision, and, consequently, its reconstruction varies. Radiation necrosis, local infective disease, or recurrent breast cancer disease have significant bone destruction, muscle, soft tissue, and skin. The provision of all the 
components is mandatory for an excellent reconstruction (2).

Significant defects of the anterolateral chest wall and sternum warrants a modulated surgical approach aiming for a stable skeletal reconstruction. The main concern for a correct surgical procedure is to preserve underlying structures, to avoid paradoxical breathing and flail chest, and, last but not least, to offer good functional and cosmetic results (2). Skeletal stability can be obtained, unless with autogenous tissue or synthetic material.

In the pioneering era of chest wall surgery, the resection of the affected area of the chest wall was limited by the availability of suitable materials. The decision concerning how to reconstruct the defect was in jeopardy by the utilization of prosthesis that did not guarantee a durable and functional surgery.

Thanks to the introduction, in the past two decades, different synthetics or biological materials have improved the surgical techniques and allows wide chest wall resection and reconstruction with adequate morbidity and mortality (1).

\section{Methods}

From January 2017 to October 2019, four patients with anterior chest diseases underwent surgical treatment:

(I) Two young patients, one with displaced traumatic sternum fracture and the other with pectus carinatum-excavatum, treated by anterior chest wall resection and reconstruction with absorbable pin and titanium plating application;

(II) Two adult patients with previous breast cancer.

\section{Case 1}

Pigeon breast is an uncommon type of anterior chest wall abnormality $(3,4)$. We herein present a case in which a severe pigeon chest wall defect that was favorably corrected by several chordotomies, a triple resectional sternal osteotomy, and stabilized with spongious bone infibulation utilizing absorbable Grand-Fix and with titanium bars on the cortical surface of the sternum and ribs.

A 20-year-old man presented with a stubborn pigeon breast. A transverse mini-clamshell incision was performed in the 5th intercostal space following the lines of Langer. By loosening the skin and subcutaneous tissue, the pectoralis major muscles were bilaterally divided on their sternal attachments and retracted in order to gain a good appearance of the chest wall deformities.

The sternum was released on his whole length bilaterally by sub-perichondrial resections from the second to the sixth deformed costal cartilages. Three osteotomies were performed on the surface of sternum:

(I) Anterior wedge of the cortico-spongious part of the curved angle of the deformed sternum;

(II) Incision the upper part of the manubrium above the angle of Louis;

(III) Incision of the lower part of the body of the sternum.

The second and the third osteotomies were then approximated and fixed with two A bioabsorbable Poly-LLactide (PLLA) pin (Grand-fix, Gunze Co., Ayabe, Japan) (5).

The soothed cartilages were newly approximated to the sternum by suturing them with polydioxanone N. 2 (Ethicon Inc, Johnson \& Johnson International, Brussels, Belgium, Europe). Finally, the superior reconstruction was fixed with Synthes Titanium Sternal Fixation (DePuy Synthes ${ }^{\circledR}$ titanium system, Monument, CO, United States). A connecting bar to stabilize the sternal-rib junction was molded manually to the curvature of the chest skeleton surface and placed between the second and the third osteotomy (Figure 1). The pectoralis muscle flaps were reattached over the sternal reconstruction.

The patient was extubated at the end of the procedure and was discharged on postoperative day 9 with an oral analgesic therapy regimen. Computed tomography (CT) follow-up at 4-month showed good results (Figure 2).

\section{Case 2}

The majority of sternal fractures $(>95 \%)$ are treated conservatively. However, in the case of unsteady fractures, thoracic wall instability, sternal deformity, respiratory insufficiency, severe pain, and non-unite fractures due to the extensive dislodgement of the bone with the surrounding soft tissue, surgical fixation could be performed. Several fixation methods have been described in the literature (6-8).

We report a case of a 15 -year-old man with a transverse fracture of manubrium after a sportive trauma. The patient referred to our department for persistent pain. Before surgical treatment, a three-dimensional reconstructed computed tomography was taken out to get detailed information on the morphology of the sternal dislodgment (Figure 3).

A T-incision obtained access to the manubrium and the sternum, was obtained through a collar tranverse skin incision coupled with a median cut from the jugular notch to the Louis angle. The manubrial margins and the fracture 

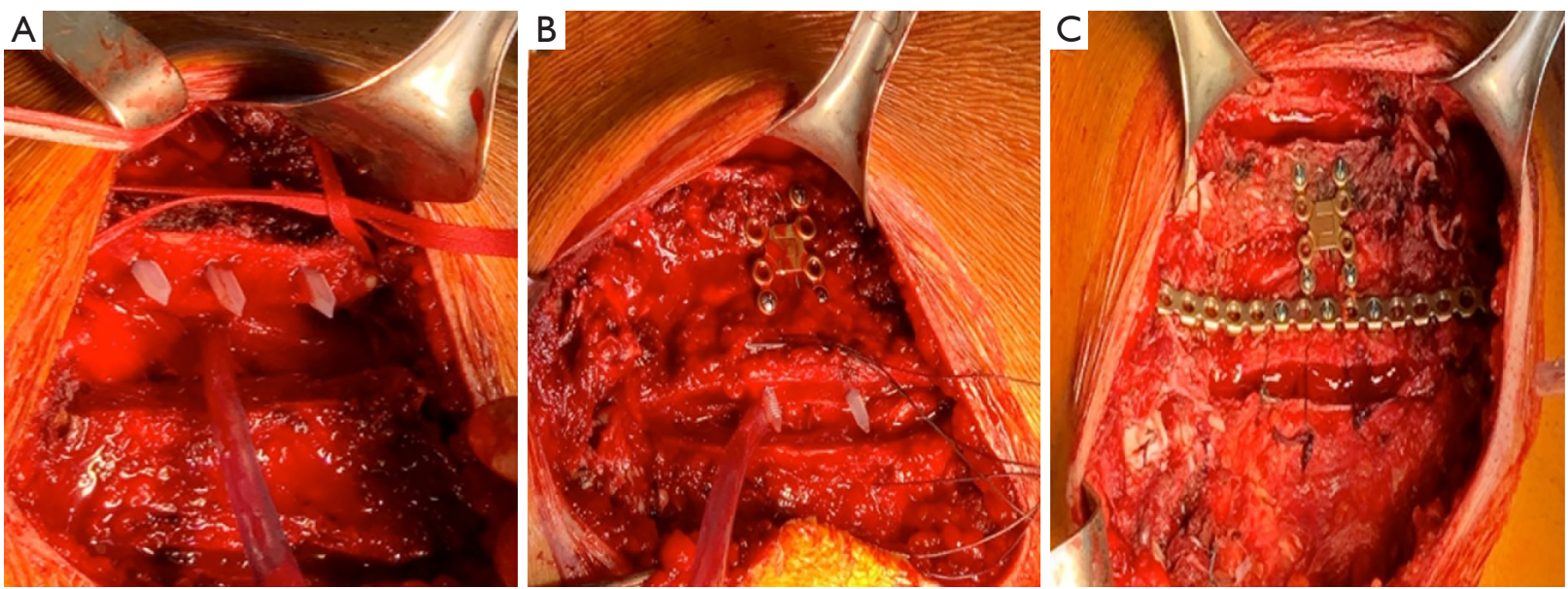

Figure 1 Case 1: surgical procedure.
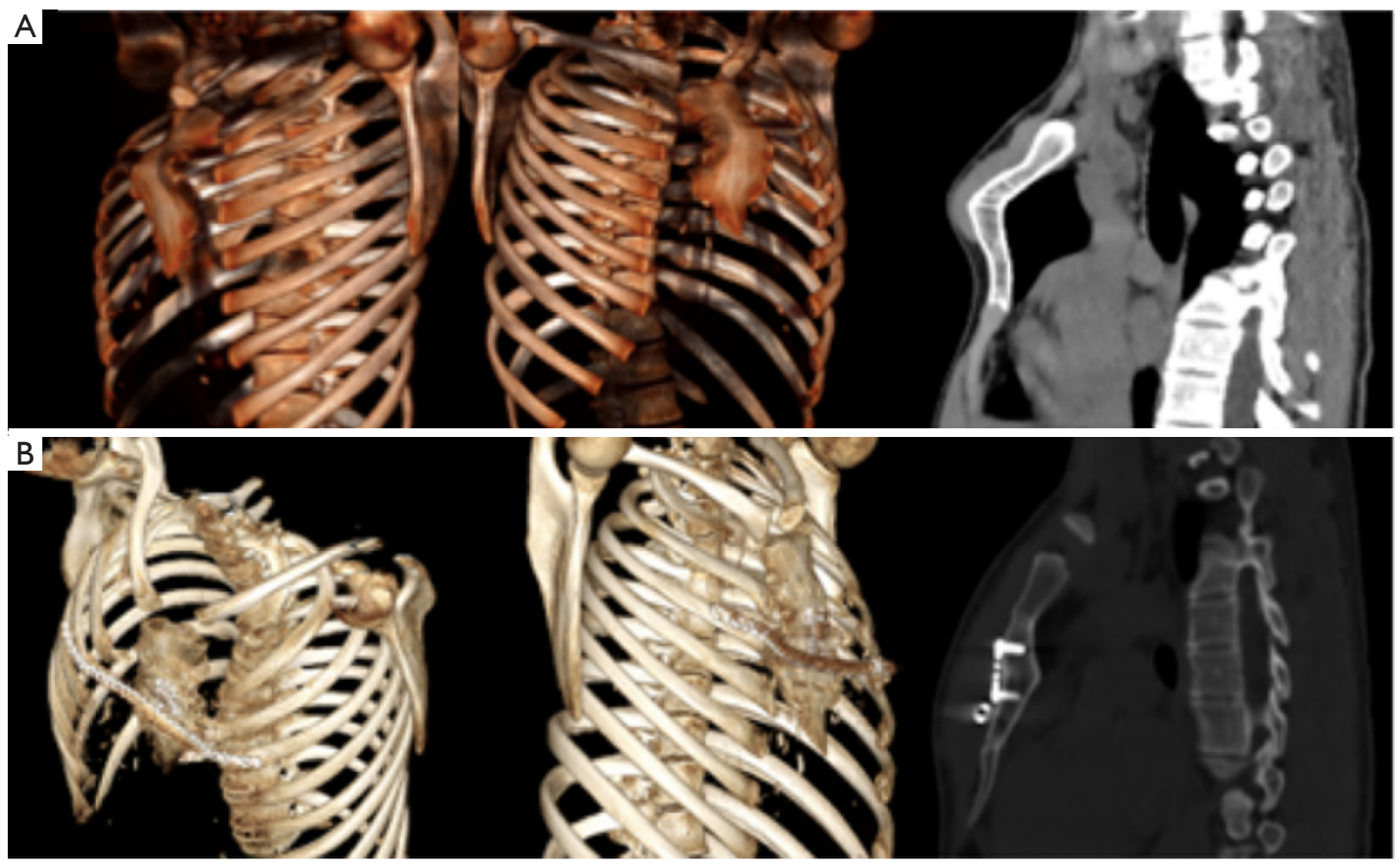

Figure 2 Pre- and post- operative CT-scan. (A) Pre-operative VRT and sagittal view. (B) Post-operative (at 4 months) CT-scan. CT, computed tomography; VRT, volume rendering technique.

site was wholly exposed. Any trapped soft tissues were removed from the fracture to ensure anatomical reduction. Internal fixation was carried out by two bioabsorbable PolyL-Lactide (PLLA) pins (Grand-fix, Gunze Co., Ayabe, Japan) (Figure 4). Two longitudinal titanium plates were then used to fixed the transverse fracture. We decided to use parallel longitudinally oriented plates for eventually future sternotomy.

The postoperative course was uneventful, and the patient was discharged after 4 days (Figure 5). 

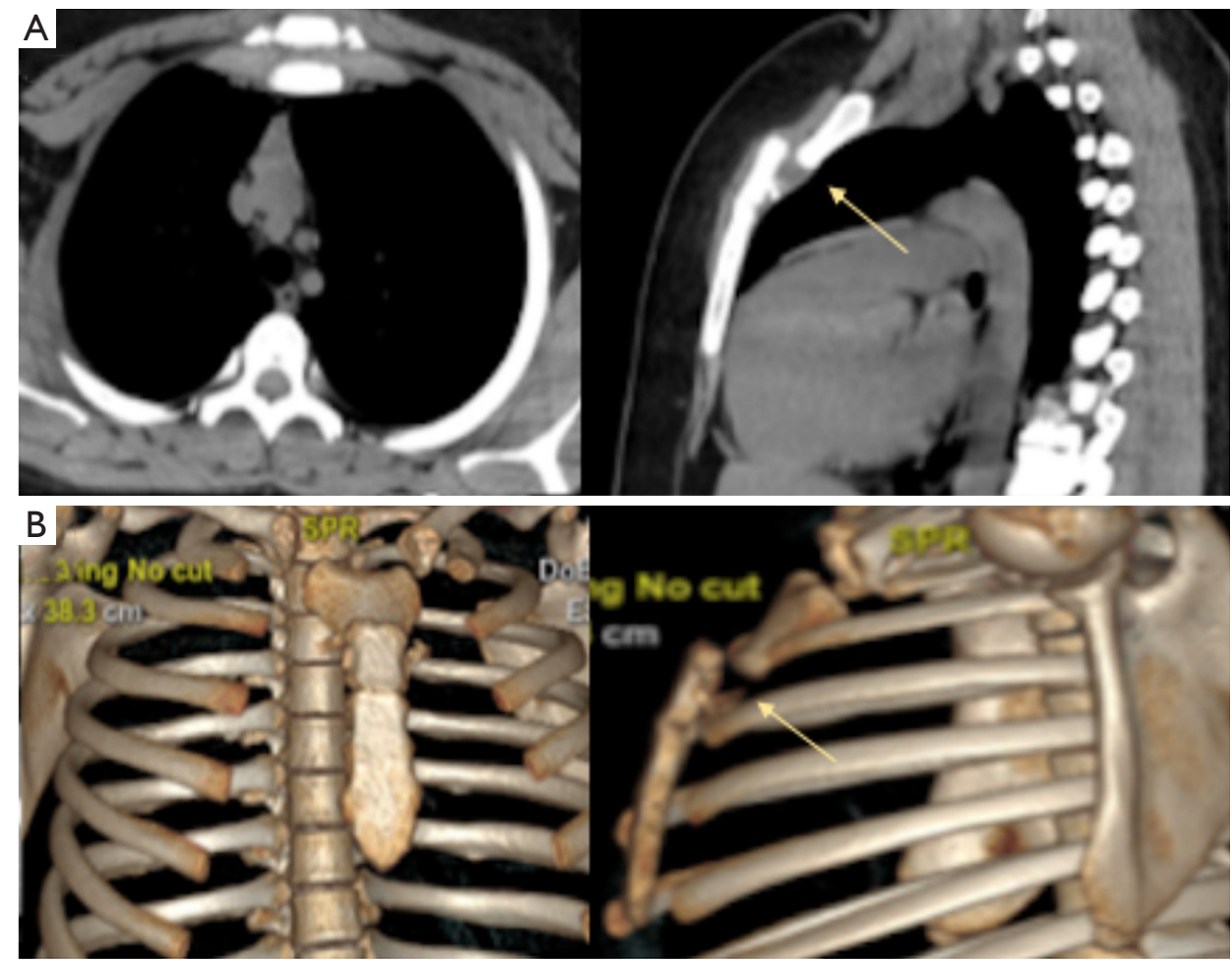

Figure 3 Pre-operative CT-scan. (A) The axial and sagittal view shows anterior-posterior dislocation or sternal kinking. (B) VRT gives an overview of the entire anterior chest wall showing manubrium fracture. CT, computed tomography; VRT, volume rendering technique.
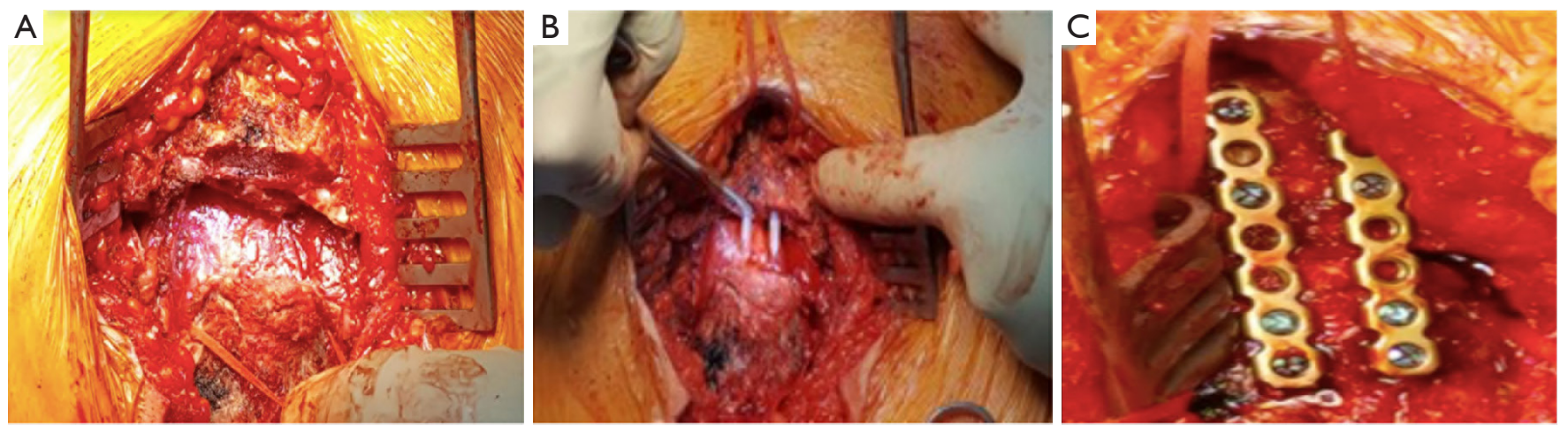

Figure 4 Surgical procedure of Case 2.

\section{Case 3}

Post-radiation sarcomas are uncommon complications of radiation therapy (RT) that may befall after many years of latency (9). Although adjuvant RT after breast surgery embodies a pivotal role in the therapy of early-stage breast malignancy (10), sarcomas of the soft/muscle and bone tissues of the chest cage have been described as a limited complication of RT for breast tumor $(10,11)$.

We present the case of a 50-year-old woman with a history of a present illness of invasive ductal carcinoma (pT2N3M0, Stage IIIC, 8th AJCC Classification System), treated with left mastectomy plus axillary lymph node dissection and postoperative adjuvant chemo/radiation therapy. Eleven years after the initial RT treatment, the patient present sternal pain, and a CT scan procedure 

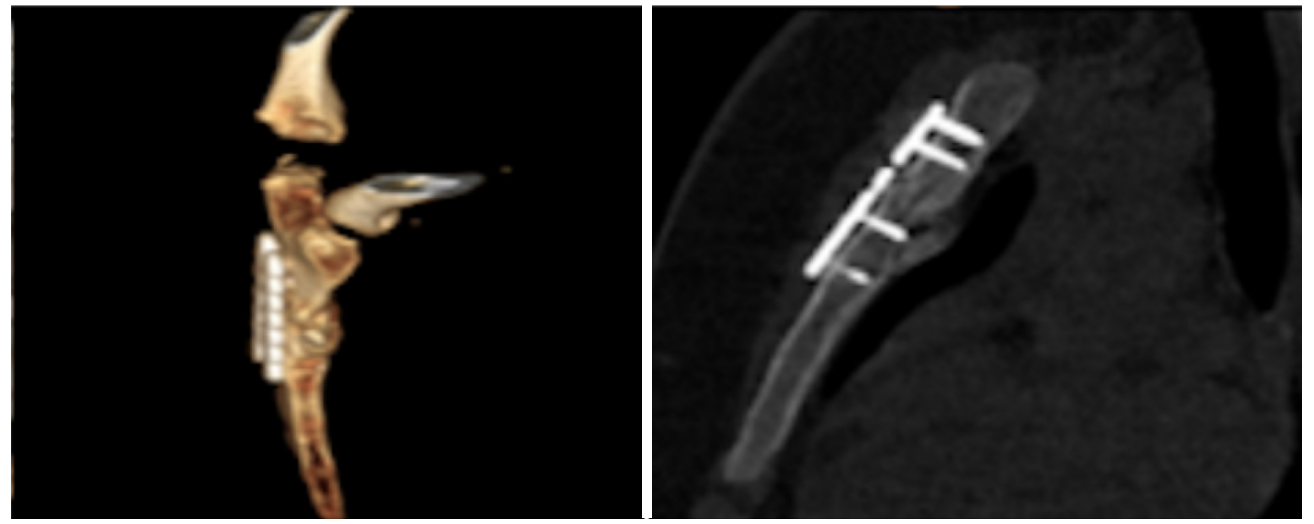

Figure 5 Post-operative CT-scan VRT and sagittal CT-scan after reconstruction. CT, computed tomography; VRT, volume rendering technique.
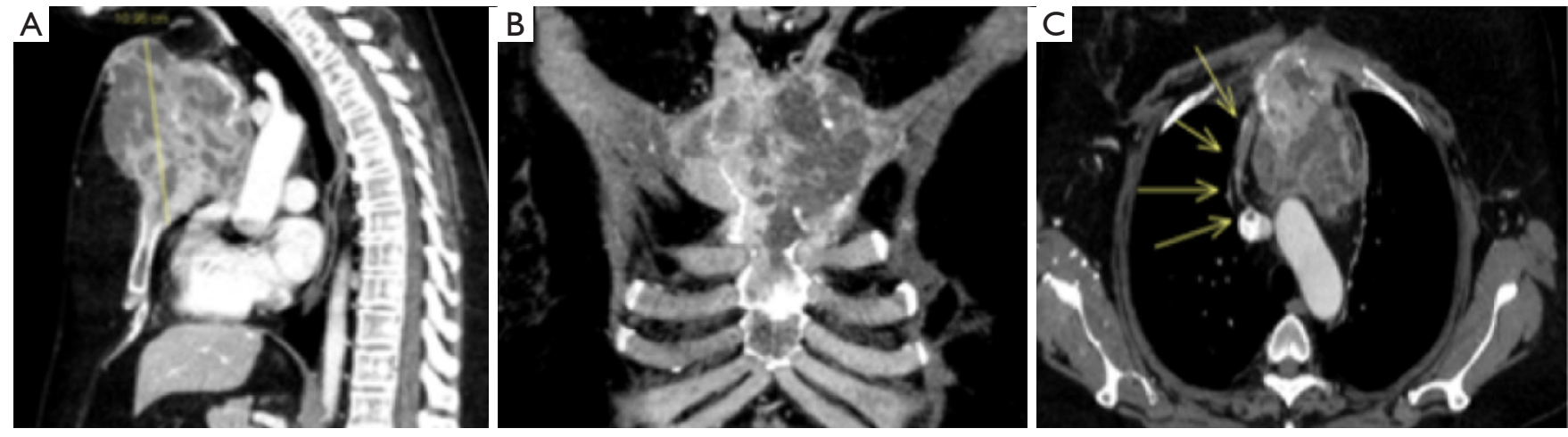

Figure 6 Preoperative CT-scan. Sagittal (A), coronal (B) and axial (C). CT, computed tomography.

was scheduled. The CT scan of the chest with iodine contrast enhancement revealed a bony tumor (Figure 6) of the manubrium and superior body of the sternum where the Louis angle usually is allotted. The neoplasm extends to 2-4 ribs-costo-cartilaginous junctions bilaterally with mediastinal and pericardial involvement. The lesion was hypermetabolic on positron emission tomography (PET).

The treatment consisted of partial removal of the sternum (the inferior part of the bone was preserved). A resection of the costal cartilage tract from the second to the fourth rib bilaterally was carried out. The medial portion of both clavicle and the anterior pericardium were removed. Hence, peritumoral soft tissue was excised en bloc, and intraoperative frozen section confirmed negative margins.

The pericardium was reconstructed with a polytetrafluoroethylene patch (PTFE, GORE-TEX ${ }^{\circledR}$, Flagstaff, AZ, United States) thickness $0.1 \mathrm{~mm}$. To rebuild the chest wall, we chose the combination of a durable mesh (synthetic ones) and titanium implants. A large piece of Gore-tex membrane, thickness $2 \mathrm{~mm}$, was first secured circumferentially to bony margins using interrupted nonabsorbable sutures under maximum tension. This approach enables a flexible barrier that guarantees a reasonable degree of protection of the two lungs and the mediastinum from the superficial tissue (Figure 7). The second step was to re-establish the rigidity of the chest wall using titanium plates. Three contoured reconstruction plates (DePuy Synthes ${ }^{\circledR}$ titanium system, Monument, CO, United States) fixated to the second and fourth ribs bilaterally (Figure $7 A$ ) and to the clavicle with Sternal ZIPFIX ${ }^{\circledR}$ System (DePuy Synthes ${ }^{\circledR}$ titanium system, West Chester, PA, United States) (Figure 7B). To cover the anterior chest defect, we used bilateral pectoral flaps.

Post-operative was characterized by partial skin necrosis and infection, with subsequent right pneumothorax that required placement of chest draining tube. The patient underwent a redo surgery consisting of debridement and 

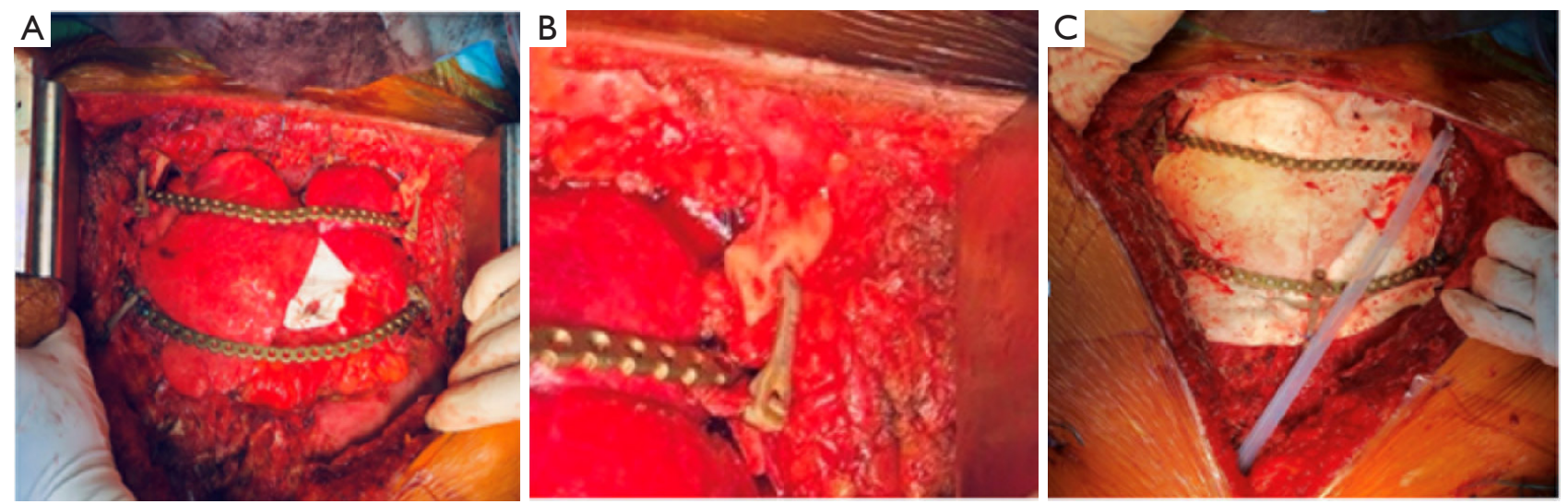

Figure 7 Surgical procedure of Case 3. (A) Titanium plates placement; (B) Zipfix; (C) Goretex under titanium implants to cover lungs and mediastinum.

primary closure with a mio-cutaneous flap of latissimus dorsi. Final pathology confirmed radio-inducted osteosarcoma. The follow-up, after 2 years, demonstrates an excellent cosmetic result and absence of recurrence disease.

\section{Case 4}

A 67-year-old woman, with an infection of the left anterior chest wall extended from the cutaneous plane down to the pleural cavity, with sternochondral osteomyelitis, presented at our Surgical Clinic for a consult. The patient had a history of previously treated invasive breast carcinoma by mastectomy with axillary lymph nodal dissection, followed by adjuvant chemo and radiation therapy.

One year later the breast surgery, the patient underwent a bilateral additive mastoplastic, complicated by infection. After about a week, the left breast implant was removed due to the onset of skin necrosis supported by Pseudomonas aeruginosa extensively drug-resistant (XDR). Several cycles of chemotherapy followed without any success.

We discussed the case with plastic surgeons and the infectious disease colleagues to anticipate potential intraoperative complications and mutually developed an adequate plan. We all decided not to implant synthetic materials for underlying infection and osteomyelitis (12), and therefore we unanimously considered auto-grafts the best tool for body repair in her case.

Tissue samples from the ulcer tissue were retrieved intraoperatively and sent off for bacterial culture and antibiotic sensitivity testing. The samples were utilized to detect the best choice of post-operative antibiotics and cease or added on the pre-operative empiric treatment. After the resection of the chest wall fistula and the surrounding scarred skin, alongside with the chest wall necrotic tissues, and the second and third rib anterior segments with the upper part of the sternum were resected. The exposure of the healthy chest wall tissue and the visceral pleura (Figure $8 A$ ) was carried out along with the pleural debridement. Ultimately, a pedicled transverse rectus abdominis muscle (TRAM) flap was harvested and used to fix the chest wall defect (Figure 8B,C). Two days later, necrosis occurred, requiring reoperation to change the flap (Figure $8 D$ ).

As an alternative, to cover the defect, a latissimus dorsi muscle flap was used (Figure 9A) but, after four days, necrosis occurred again (Figure 9B).

The great omentum was therefore uprooted through a subcutaneous tunnel from the abdomen to the thorax using the laparoscopic approach. The diaphragm operculum was made to be roomy enough to maintain the blood supply of the great omentum once was transferred in the anterior chest wall defect. The great omentum pedicle was then covered by a skin graft taken from the right thigh. However, due to new partial necrosis, we brought the patient for the fourth time in the operating room (Figure 10).

A free flap from the left thigh was harvested. The vessels from the graft were anastomosed, with a magnified view, end-to-end to the lower thyroid artery and internal jugular vein. The donor site was then primarily closed.

Lastly, there were no post-operative problems related to vascularization of graft. Finally, the patient slowly and steadily recovers from the surgical procedures.

Since this work is a retrospective study no ethics committee approval and patient informed consent was needed. The study was conducted in accordance with the 

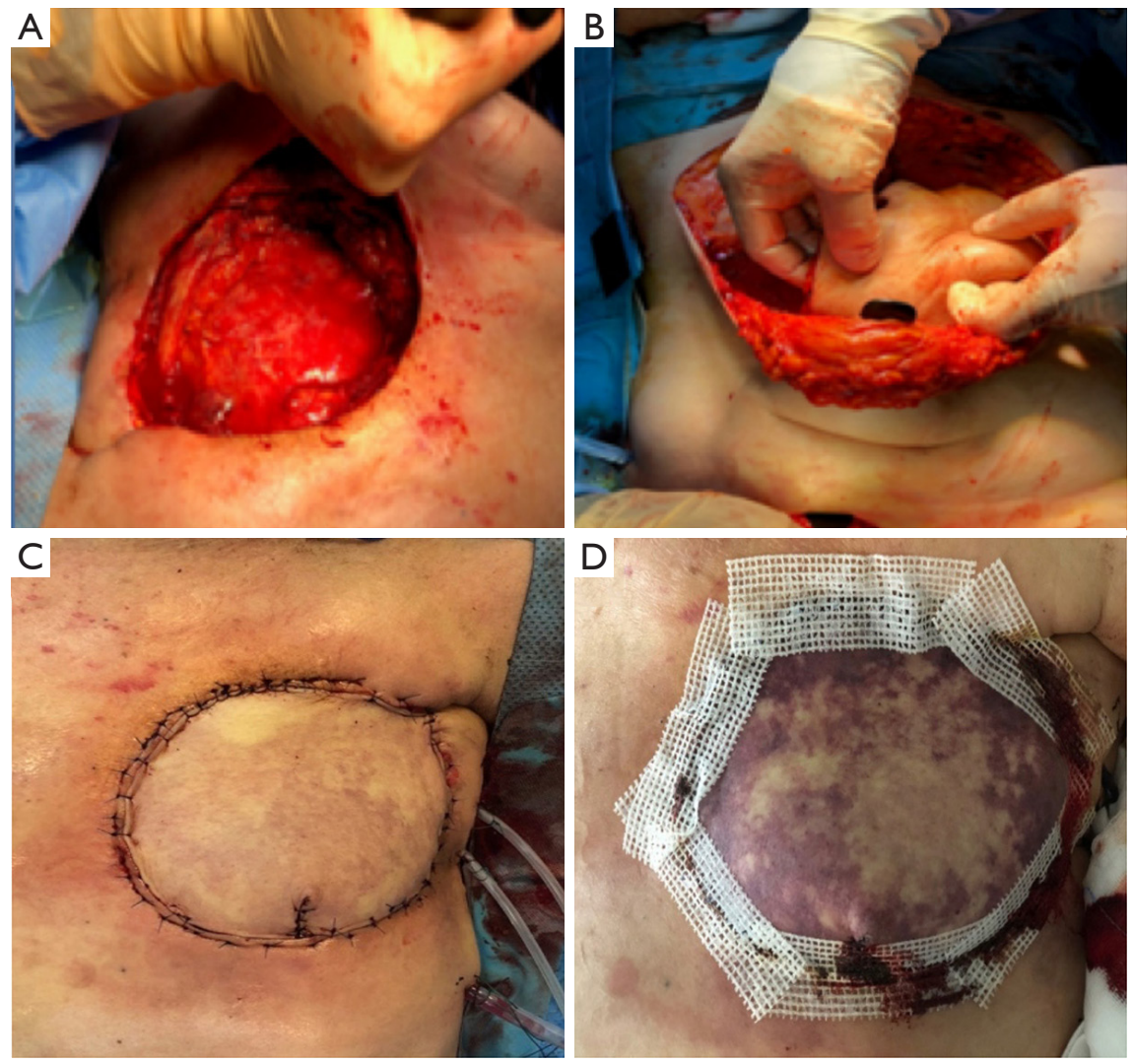

Figure 8 Surgical procedure of Case 4. (A) Debridement; (B) pedicle transverse rectus abdominis muscle flap rotation; (C) post-operative reconstruction; (D) necrosis of flap after 2 days.
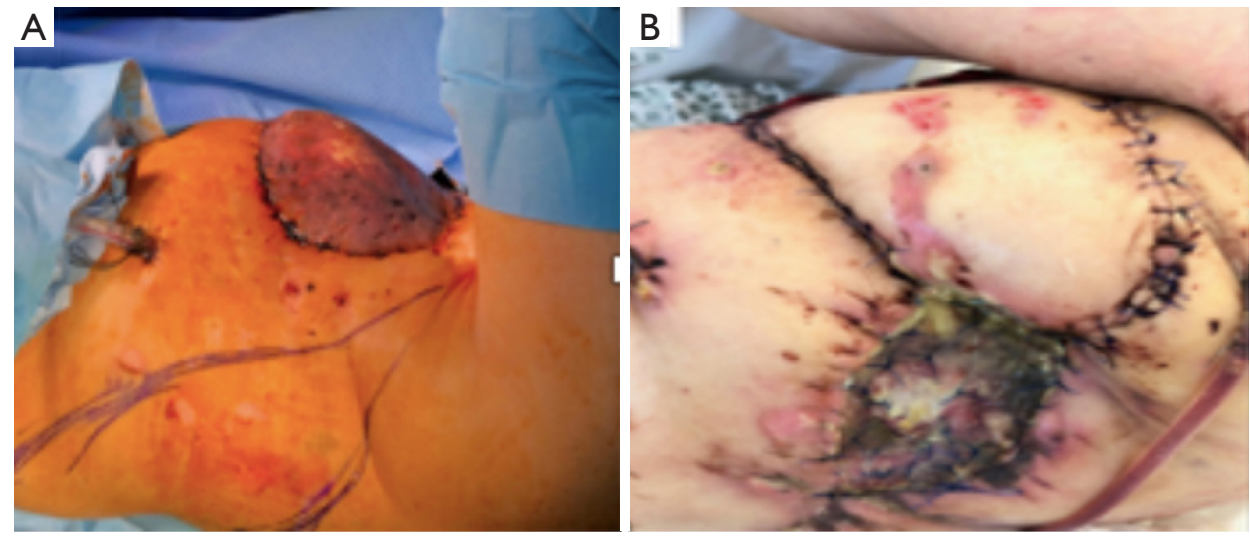

Figure 9 Surgical procedure of Case 4: the first re-do. (A) Latissimus dorsi flap; (B) second flap failure.

Declaration of Helsinki (as revised in 2013).

\section{Results}

Of these four patients with anterior chest diseases, we had different results between the two groups.

In both two young patients, one with displaced traumatic sternum fracture and the other with pigeon chest, we had good results correcting deformities and then fixing it by using a combination of different materials. 

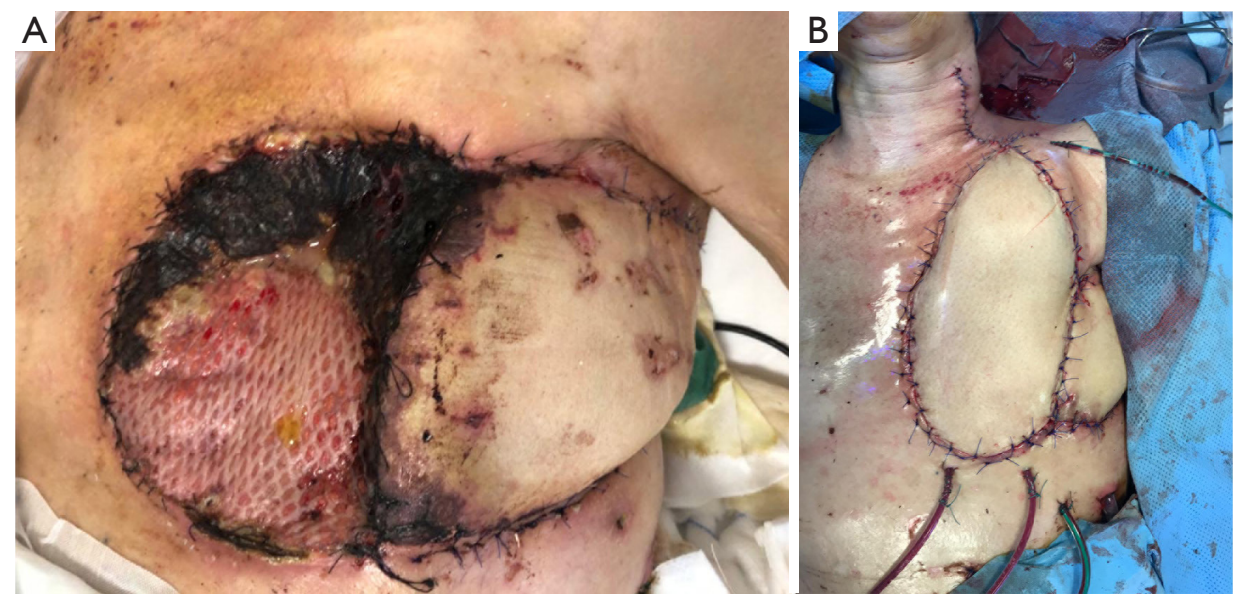

Figure 10 Case 4 surgical procedure: the third re-do. (A) Omental flap necrosis; (B) free fascial graft from the lateral thigh.

As already shown, follow-up CT confirms the good cosmetic outcome, with a satisfactory reconstruction and regular movement. Both patients and parents describe an improved emotional comfort and self-confidence, as well as an increased physical and welfare activities from pre- to post-surgery.

The postoperative course was complicated in the oldest two patients that underwent previous surgery and radiotherapy for breast cancer. Both cases had skin dehiscence and needed further surgical revision.

\section{Discussion}

Deformities of the anterior chest wall can happen as a consequence of congenital malformations, trauma, neoplasm (such as metastatic or primary tumors), radiation treatment, and infection.

There is some disagreement as to which chest wall lesions should be repaired but, commonly, injuries smaller than $5 \mathrm{~cm}$ in extent in any location, and those up to $10 \mathrm{~cm}$ in dimension posteriorly allocated do not need repair for functional reasons (3).

Over the years, several surgical procedures have been described, comprising various materials for chest wall repair or stabilization. What is of paramount importance, in particular after extensive chest wall resection, is to: ensure an optimal stabilization and support of the thoracic cage, avoid respiratory failure, paradoxical respiratory movement, thoracic organ herniation, prevent chronic post-operative pain and gain acceptable cosmetic results (1). Optimal results are achieved using a combination of rigid and biological prosthetic materials (13) or autogenous tissue.

We herein reported a small case series of 4 patients treated for four different diseases with four different techniques. The choice of the type of implant was made according to what are the characteristics of ideal prosthetic material as stated by Le Roux and Shama (2):

(I) Rigidity to abolish paradoxical movement;

(II) Inertness to allow in-growth of fibrous tissue and decrease the likelihood of infection;

(III) Malleability so that it can be fashioned to the appropriate shape at the time of operation;

(IV) Radiolucency to allow radiographic follow-up of the underlying problems.

With these principles in mind, we used a different kind of material, always in combination, to cover and protect underlying structures and prevent flail chest and paradoxical breathing.

Furthermore, we would like to highlight how these materials, commonly used in other specialties, can be led to a synergistic activity with patches or titanium plates/ mesh for an optimal outcome in thoracic surgery chest wall reconstruction/stabilization scenarios.

The idea, behind the absorbable bone fixation device made of PLLA (poly-L-lactic acid) we used as bone medullary infibulator, is to help to greatly stabilise the work of the titanium bars. The Zipfix System was created to enables fast sternal closure. The system chiefly consists of PEEK (polyetheretherketone). It is easy to apply, biocompatible, and compatible with magnetic resonance after removal of stainless steel needle. We used this material 
to fix the clavicular joint and rib plates.

The 3D scan had a pivotal role in the success of our reconstructive chest surgery by helping us to correct the surgical approach based on the spatial distribution of the diseased area to correct or remove.

Lastly, a multidisciplinary planning, along with a rational surgical approach leads to good results and to find the right solution in case of complications, as reported in our small case series.

\section{Acknowledgments}

We would like to thank Mrs Simonetta Padovani and Mrs Nadia Lanni for their outstanding work in collecting clinical data and manage with great professionalism and empathy the intereactions with our patients and their family.

Funding: None

\section{Footnote}

Provenance and Peer Review: This article was commissioned by the Guest Editors (Francesco Zaraca, Reinhold Perkmann, Luca Bertolaccini and Roberto Crisci) for the series "Thoracic Surgery Without Borders" published in Current Challenges in Thoracic Surgery. The article has undergone external peer review.

Conflicts of Interest: All authors have completed the ICMJE uniform disclosure form (available at https://ccts.amegroups. com/article/view/10.21037/ccts.2020.02.05/coif). The series "Thoracic Surgery Without Borders" was commissioned by the editorial office without any funding or sponsorship. ND serves as an unpaid editorial board member of Current Challenges in Thoracic Surgery from February 2020 to January 2022. The authors have no other conflicts of interest to declare.

Ethical Statement: The authors are accountable for all aspects of the work in ensuring that questions related to the accuracy or integrity of any part of the work are appropriately investigated and resolved. Since this work is a retrospective study, no ethics committee approval and patient informed consent was needed. The study was conducted in accordance with the Declaration of Helsinki (as revised in 2013).

Open Access Statement: This is an Open Access article distributed in accordance with the Creative Commons
Attribution-NonCommercial-NoDerivs 4.0 International License (CC BY-NC-ND 4.0), which permits the noncommercial replication and distribution of the article with the strict proviso that no changes or edits are made and the original work is properly cited (including links to both the formal publication through the relevant DOI and the license). See: https://creativecommons.org/licenses/by-nc-nd/4.0/.

\section{References}

1. Sanna S, Brandolini J, Pardolesi P, et al. Materials and techniques in chest wall reconstruction: a review. J Vis Surg 2017;3:95.

2. Hameed A, Akhtar S, Naqvi A, et al. Reconstruction of complex chest wall defects by using polypropylene mesh and a pedicle latissimus dorsi flap: a 6-year experience. J Plast Reconstr Aesthet Surg 2008;61:628-35.

3. Brichon PY, Wihlm JM. Correction of a Severe Pouter Pigeon Breast by Triple Sternal Osteotomy with a novel titanium rib cage fixation. Ann Thorac Surg 2010;90:e97-9.

4. Lam CR, Taber RE. Surgical treatment of pectus carinatum. Arch Surg 1971;103:191-4.

5. Saito T, Iguchi A, Sakurai M, et al. Biomechanical study of a Poly-L-Lactide (PLLA) sternal pin in sternal closure after cardiothoracic surgery. Ann Thorac Surg 2004;77:684-7.

6. Athanassiadi K, Gerazounis M, Moustardas M, et al. Sternal fractures: retrospective analysis of 100 cases. World J Surg 2002;26:1243-6.

7. Severson EP, Thompson CA, Resig SG, et al. Transverse sternal nonunion, repair and revision: a case report and review of the literature. J Trauma 2009;66:1485-8.

8. Queitsch C, Kienast B, Voigt C, et al. Treatment of posttraumatic sternal non-union with a locked sternumosteosynthesis plate (TiFix). Injury 2011;42:44-6.

9. Cahan WG, Woodard HQ, Higinbotham NL, et al. Sarcoma arising in irradiated bone: report of 11 cases. Cancer 1948;1:3-29.

10. Veronesi U, Cascinelli N, Mariani L, et al. Twentyyear follow-up of a randomized study comparing breastconserving surgery with radical mastectomy for early breast cancer. N Engl J Med 2002;347:1227-32.

11. Yap J, Chuba PJ, Thomas R, et al. Sarcoma as a second malignancy after treatment for breast cancer. Int J Radiat Oncol Biol Phys 2002;52:1231-7.

12. Zhou Y, Zhang Y. Single- versus 2-stage reconstruction for chronic post-radiation chest wall ulcer. A 10-year 
retrospective study of chronic radiation-induced ulcers. Medicine 2019;98:e14567.

13. Tamburini N, Grossi W, Sanna S, et al. Chest wall reconstruction using a new titanium mesh: a multicenters experience. J Thorac Dis 2019;11:3459-66.

doi: $10.21037 /$ ccts.2020.02.05

Cite this article as: Giunta D, Daddi N, Antonacci F, Pinto V, Solli P, Dolci G. Anterior chest wall reconstruction for oncologic and non-oncologic pathology: a case series. Curr Chall Thorac Surg 2020;2:24. 